\title{
Building of a Hierarchical, Open, Team- oriented Physics Experiment Teaching Mode to Train the Innovative Ability of College Students
}

\author{
Limin An \\ Center for Basic Physical Experiment, Heilongjiang University, Harbin, 150080, China \\ Email: anlimin@hlju.edu.cn
}

\begin{abstract}
The college physics experiment teaching is very important to develop the ability of innovation and the scientific literacy of students. According to experiment skills and scientific thinking we design experiments with four levels, such as basic experiment, comprehensive experiment, designing experiment and research experiment. The labs are open all the time. The students can choose the experiment contents, research the information, design scheme, make the process and complete the experiment according to their interests and abilities. It realizes a personalized open teaching mode. Relying on science and technology innovation platform for students we build the project team, the teacher's team and the student's team to create an all-around team training mode. The innovation ability of the students has been improved with the hierarchical, open, team-oriented experimental teaching mode.
\end{abstract}

Keywords: physical experiment, hierarchical, open, team-oriented, innovation ability

University physical experiment is a compulsory course for all students major in science and technology, physics is a laboratory course, the development and innovation of physics are closely related to the experiments, from the cant ball drop experiment of Galileo to Newton's three laws of motion, from the electromagnetic induction experiment of Faraday to the creation of Maxwell's electromagnetic theory, these laws and theories are directly obtained from the observation, analysis of a large number of experiments, the validity of these theories are all verified by the experiments, there are many arguments in the history of physics, such as the special relativity and the general relativity, they are finally use experiments to judge whether they are right or wrong. Therefore, as an important basis, an important content and an important method, the physical experiments have an important position and an important function in physics teaching, the physical experiment teaching is very important to improve the innovation ability and the scientific literacy of the students ${ }^{[1]}$.

Physics experiment is not only a course to simply train the students' skills, but also contains a lot of epistemology and methodology, do a good job in physics experiment teaching is not only benefit to improve the students' experimental skills, but also can inspire and cultivate the students' scientific thinking methods and the innovation ability, inspire the students' interests in scientific research, improve the students' scientific literacy. Therefore, 
it is necessary and feasible to cultivate the students' scientific literacy, improve the students' innovation ability through the physics experiment teaching ${ }^{[2]}$.

It starts with improve the students' scientific literacy and innovation ability, the university physical experiment teaching should be built a set of systematic education according to the inherent law and order of the course, it can cultivate the students' scientific literacy by the teaching mode of the experiment teaching, according to the different stages of the ability and the understanding of the students, take the reasonable knowledge structure to carry out a hierarchical, personalized, open teaching mode ${ }^{[3]}$. The physical experiment center of Heilongjiang University carries out the reform exploration of to cultivate the students' innovation ability, it creates a new teaching mode for cultivate innovative talents by this hierarchical, open, team-oriented teaching mode. This kind of teaching mode use different teaching methods with different levels, bring the new technology, new knowledge of the modern world in the experimental class, students can choose the experiments according to their interests and abilities, so they can complete the experiments by themselves, completely break the traditional machine-made, enclosed teaching mode, realize a personalized, open teaching mode, it is conducive to cultivate high-quality talents ${ }^{[4]}$. Therefore, for improving the students' innovation ability concerns, the layered open team-oriented teaching mode is greatly needed.

\section{Hierarchical physical experiment teaching mode}

Physical experiment contents can be divided into four different levels, that is, basic experiment, comprehensive improved experiment, designing experiment and research experiment, there are four levels of experiment skills, scientific thinking and teaching modes.

The first level is mainly including the measurement of basic physical quantity, the use of the basic experimental instruments, training the basic experimental skills, the basic measurement method and error analysis, it relates to the knowledge of force, heat, light and electric. In this level, the teacher will highlight the key points and the difficult points of each experimental questions, and pay much attention on cultivate the students' basic experimental skills, scientific measuring method and the scientific attitude of seeking truth from facts, to lay a solid foundation for the whole experiment learning, it is a required course of all the students.

The second level is to open some comprehensive, elevated and modern technological experiments, gradually increasing the depth, difficulty and breadth of the experiments. In this level, the teacher mainly explains the design ideas of the experiments, leads the students to complete the experiments by themselves, this level is mainly consolidating the learning outcomes of basic experimental study, expanding the students' horizons and thoughts, improving the comprehensive utilization ability of experimental methods and experimental technologies, it requires the students to do a certain number of selected questions.

The third level is designing experiment, in this level, students can choose experiments, they can look information up, determine the experiment schemes, choose experimental instruments, design experimental steps, measure experimental data, deal with experimental data and analyze the experimental results by themselves, the teacher only acts as a role to motivate, guide the students, students are all active learning. The purpose of the designing experiments is to inspect the experimental skills and the theoretical knowledge of the students, it can reflect the students' 
ability of comprehensive use knowledge and of solve problems, the experiments in this level is set an elective course for the students who are interested in physics.

The fourth level is the research experiment, this level is mainly cultivating the students' innovation thinking and innovation ability, it needs outstanding undergraduates and graduate students take part in the subprojects of the teachers' scientific research projects, they can also discuss with the teachers to set up their own research project. To build a platform of the students' academic science and technology innovation projects and innovation laboratory projects, complete the application, opening, in-process inspection and conclusion of the projects, as a result of publishing papers, applying for patents, creating material objects, taking part in competitions.

\section{Physical experiment of open teach- ing mode}

The physical experiment center of Heilongjiang University carried out the practice of open teaching, to improve the network management platform of the experiments, to enact a series of measures, actively seeking the scientific management of experimental teaching to ensure the open experiment teaching going on wheels.

This is a teaching mode that the students as the main body, the teachers as the leadership, and based on the selfstudy of the students. As for the form aspect, the open experiment teaching mode refers to open the experimental time, the experimental classroom and the laboratory equipments. As for the depth aspect, it refers to provide the space for students to choose experimental subjects and experimental schemes. The experiments' contents are divided into required courses and optional courses. There are some basic experimental contents in the re- quired courses, they are required every student to complete them, the students can choose the experimental time by themselves; the optional courses contain some elevated, designable and researchable experimental contents, for the students who are study better than others can choose the experiments they are interested in. In addition, it is supported by the open laboratory project, the innovation laboratory project and academic science and technology innovation project, to encourage students go into the open laboratories for doing research into academic scientific research projects. This experimental teaching mode is not only open on the time and equipments, but also opens the experimental contents, and it is benefit to the students' individuation, rivalry and enthusiasm on the experiments. There is no doubt that this kind of teaching mode is worth promoting. But it has conflict between the physical truth and this teaching mode, between the increasing workload and the lack of teachers, between the increasing spoilage of the equipments and the funds tension of the equipments. The physical experiment center of our school increases the funds investment, improves the management of the instruments, and increases the number of part-time experimental teachers with the support of relevant fund project, in order to guarantee the open of the laboratory with the highest efficiency.

\section{Team-oriented mode to cultivate students' innovation ability}

In the physical experiment teaching, it is a system engineering that how to guide the students who know the basic theories well to have productive thinking, take part in the innovative work. Through the reform practice, we built a full range of team training mode, set up the teachers' teams, the students' teams and the projects' teams. 
(1) In the process of cultivating the students' innovation ability, the teachers play a leading role that decides the quality of the students. But, on the one hand, with the development of modern science technology and the contents of the majors, and at the same time, the relation between different disciplines became more and more, so it requires the teacher has multidisciplinary knowledge, but only one teacher is difficult to do that. Although there are some universities adopt the graduate education that the advisor is responsible for the graduate students and combined with other teachers to cultivate the graduate students, but due to the difference of cognition and the lack of system, its function is not work. Therefore, it is necessary to establish a real teachers' team to overcome the lack of a single teacher system, such as the academic inheritance relationship is singleness, it is easy to form the academic prejudice, and it limits the academic field of vision. Therefore, it is very important to build teachers' team, clear responsibilities, to take effective measures to carry out this mode in order to improve the quality of the students.

The academic leader acts as the headman, the experienced professors, associate professors and doctors act as team members, at the same time, let some technicians that have the strong ability to take part in this mode. The teachers' team should clear the objectives, tasks and plans, teachers enact scientific research direction and the breakthrough point, project approval to determine the project tasks, do the task decomposition, to form a periodic task sequence with a suited difficulty in order to facilitate graduate students and good undergraduate students to choose to do. The teachers should be a clear division of responsibilities within the teachers' team, some teachers are responsible for the overall design, and the others are acting as the guidance of the specialized project tasks. And they should also scientific summarize the phased objectives, to do the necessary integration, interpretation, analysis and summary. The teachers' team entirely responsible for enacting plan, selecting an experiment project, designing the experiment, guiding the experiment, the essay writing, the device fabrication, the patent applications and the dissertation reply. Complementary advantages between these teachers will contribute to the improvement of the teachers' team.

(2) The students form a team in order to change disadvantages of 'goes it alone' of the students, to form a good cooperation atmosphere. The graduate students and the undergraduate students form different grades are constitute a team, the students are not always from one teacher, even can attract the students major in other majors. Holds regular academic progress report within the team, especially the senior students should introduce their achievements and experiences. This innovation team that the graduate students head the list of signers, with the lower grade graduate students can enhance the sustainability of the project research, strengthens the exchange between senior students and low grade students. On the one hand, it can open junior low grade students' view, sets up the innovation consciousness, and cultivates operational ability. On the other hand, it can also enhance the organizing ability, presentation skills of the senior students during scientific research. In student teams, each student should clearly know one's main research directions, at the same time, it also has the team overall objectives and the division of labor, even constitute a band carrier form.

(3) The teachers of each experiment subject form a teaching team to collective doing preparation for classes, attending the lectures with each other, doing teaching and research activities on a regular 
basis. Each academic science and technology innovation project, open laboratory project, innovation laboratory projects, the subject of challenge cup or the electronic design competition can according to the different topics and directions, to form an independent project research team, encourage graduates and undergraduate students from different grades and majors to form a team, to form a diversified, intersective, echelon construction. Under the effort of teachers and students, the project teams of physical experiment center have achieved much in innovation, students published many academic articles and take part in the competitions relate to physics and get many prizes, the innovation ability of the students developed rapidly and stably.

With the time goes on, the education idea and teaching methods updating constantly. We need to deepen teaching reform to cultivate high quality talents, such as the exploratory, researching experiment subjects, to upgrade the experimental teaching management network platform, strengthen exchanges and cooperation between different universities and different departments, set up teams between different schools or different departments, to cultivate innovative talents in a hierarchical, open, team-oriented teaching mode more efficiently.

\section{Acknowledgement}

In this paper, the research was sponsored by the 12th Five-Year Plan for the education science of Heilongjiang province (GBD 1211048), the higher education and teaching reform project of Heilongjiang province (JG2012010500), the second "Three Education" research project of Heilongjiang University (SK1216) and the degrees and graduate education reform project of Heilongjiang University (JGXM_YJS_2012025).

\section{References}

[1] Y. Shen, "efforts to cultivate innovative talents in basic physics experiment teaching," Journal of College Physics, pp. 42-44, 2000.

[2] W. An, "Promote higher order thinking ability of students in physics experiment teaching," Journal of Heilongjiang Education (Higher Education Research and Evaluation), pp. 34, 2012.

[3] E. Jin, "a few university physics experiment teaching situation in the United States and Canada," Journal of Physics Experiment, pp. 45-48, 2002.

[4] L. An, "The cultivation of the college students' practice ability and innovative quality," Century Bridge, pp. 4548, 2011. 